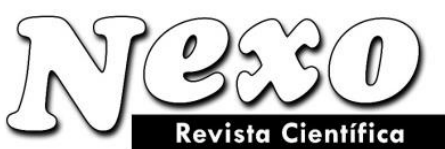

Vol. 33, No. 02, pp. 547-555/Diciembre 2020

\title{
Providing a System Based on Location Systems to Reduce Possible Earthquake Accidents
}

\section{Proporcionar un sistema basado en sistemas de ubicación para reducir posibles accidentes sísmicos}

\author{
Saeid Shahshahani \\ M.A (geophysics) Seismology, Ghom Branch, Islamic Azad University, Ghom, Iran. \\ Corresponding autor email: saeid_shahshahani@yahoo.com
}

(recibido/received: 14-July-2020; aceptado/accepted: 15-September-2020)

\begin{abstract}
The purpose of this study is to investigate the effective indexes of damage to a building, with the aim of reducing the possible events caused by the earthquake and presenting a model based on spatial information systems. So, after collecting the data and information required by field method and statistical blocks, a spatial database was obtained. Then, the effectiveness of each of the criteria was based on the creation of a binary comparison matrix and questioning experts from the subject The study was obtained. In the end, in order to establish a link between the influential factors and the estimation of the final vulnerability of each building, a formula was presented in which all the effective factors were involved with the emphasis on the level of effectiveness of each building. Using expert selection software, the indexes were evaluated in terms of weight and value. Finally, the geospatial information system of GIS evaluated the magnitude and severity of the earthquake in different ranges and its consequences in terms of the indices studied for the buildings in the study area.
\end{abstract}

Keywords: spatial information systems, events, earthquakes, GIS.

\section{RESUMEN}

El propósito de este estudio es investigar los índices efectivos de daño a un edificio, con el objetivo de reducir los posibles eventos provocados por el terremoto y presentar un modelo basado en sistemas de información espacial. Entonces, luego de recolectar los datos y la información requerida por el método de campo y bloques estadísticos, se obtuvo una base de datos espacial. Luego, la efectividad de cada uno de los criterios se basó en la creación de una matriz de comparación binaria y cuestionando a expertos del tema. Se obtuvo el estudio. Al final, con el fin de establecer un vínculo entre los factores influyentes y la estimación de la vulnerabilidad final de cada edificio, se presentó una fórmula en la que se involucraban todos los factores efectivos con énfasis en el nivel de efectividad de cada edificio. Utilizando un software de selección experto, los índices se evaluaron en términos de peso y valor. Finalmente, el sistema de información geoespacial de GIS evaluó la magnitud y severidad del sismo en diferentes rangos y sus consecuencias en términos de los índices estudiados para las edificaciones del área de estudio.

Palabras claves: sistemas de información espacial, eventos, terremotos, GIS. 


\section{INTRODUCCIÓN}

The earthquake phenomenon is one of the most devastating natural hazards that has caused a lot of damage over the course of history. Iran is geographically located in 10 countries of the world in terms of natural hazards and unexpected accidents. Iran has ranked third in terms of vulnerability to natural hazards, according to a May-Kraft report from the British company, in the period from 1980 to 2010 in 229 countries.

A look at the effects of earthquakes in recent decades suggests that on average every five years, an earthquake with severe physical and financial damage has occurred in the country that has left out longterm socio-economic effects (Entezary, 2002).

The earthquake is of great importance to its particular nature, because its abundance is greater than other natural disasters and causes many casualties and injuries. Although the earthquake has not yet been foreseen, the certainty of its occurrence in many parts of the world is indisputable. Hence, the methods of reducing the resulting lesions are always part of human research and research activities. So, as it should wait for the earthquake, it should expect the damage and the resulting damage, in other words the earthquake crisis. Hence, human efforts to confront the destructive effects of earthquakes have led to the opening of a new window of research activity called earthquake management (Amini Hosseini and Pishnamazi,2011).

The crisis is an accident that occurs suddenly due to natural and human events and actions, and imposes hardship, hardship and damage on a human set or human society, and eliminating it requires action and emergency action. As it is mentioned, one of the natural disasters in the earthquake, in fact, is the earthquake, is the seismic energy transmitted from the depths of the earth to the surface, and usually in the crust of the shear, tensile or compression (horizontal, vertical, and rotational)) Creates a strong seismic pressure. The vibrations cause the destruction and destruction of buildings, installations and the killing and wounding of people (Pishnamazi, 2015).

Although it is not possible to prevent an earthquake, it is possible to reduce the damage caused by it. What is most important is saving people's lives against this natural occurrence. The need to reduce the social, physical and economic damage caused by the earthquake is unobtrusive. Given the unpardonable nature of the earthquake, the need for rapid and correct adoption of decisions and implementation of operations, theoretical and fundamental foundations, has created a knowledge of crisis management, which reduces the effects of accidents and vulnerabilities. This is particularly relevant to urban planning and regional planning and geography. By applying the principles and definitions of the concepts in this knowledge, we can greatly reduce the effects and consequences of natural disasters. It allows the use of spatial modeling systems to reduce the probable damage caused by an earthquake (Hosseini, 2008).

Today's new generation of computer systems is equipped with sophisticated capabilities with a variety of capabilities. These capabilities may be used to solve some geographic and geophysical issues (Longley et al., 2005) .Various methods can be used to display spatial information. The use of modern technologies such as GIS has become widespread in the developed world today, and there are many studies in this area that can help in predicting vulnerable areas, as well as helping the injured and organizing post-accident situations. Using GIS analyzes, vulnerabilities can be identified against an earthquake to determine the correct planning for those ranges.

The use of systems such as spatial information systems (GIS) can be very effective in identifying crisis points by combining multi-criteria decision-making methods. Given the GIS's ability to combine ground reference data and with the possibility of performing complex analyzes of spatial and non-spatial data, GIS is the best means of determining the areas with the highest probability of crisis.

The purpose of the present study is to provide a spatial information model based on the GIS information system, which is based on the characteristics of the area under study and the estimation of the probable damages and the prediction of damages and injuries and the prevention of damages caused by the crisis. It is intended to determine the urban management based on crisis management to reduce the harmful effects of this natural disaster in the study area. 


\section{RESEARCH HISTORY}

Considering that planning to reduce the environmental impacts of the environment is always one of the most challenging issues that has been at the center of discussions among researchers and experts for about half a century, several studies have been done on this topic. Here is a review of a number of these studies on urban tissue vulnerability with the earthquake crisis management approach.

Torabi and Habibi (2010), in a study entitled "Investigating the vulnerability of cities to earthquakes using the Hierarchical Reverse Hierarchy Process (GIS), IHWP; A Case Study: Tehran Municipality 6", analyzes the vulnerability of the body of major communication networks in the region. ; The results of this study showed that the corpses of streets with high population density, low build quality, long distance to rescue centers compared with other bodies and higher degree of enclosure, have brought high vulnerability points and As a result, they are more vulnerable, and they have come up with solutions at the end.

Prevention of Individual and Associates (2011), in an article entitled "Modeling the Determination of Risk Areas Using the AHP Model in the GIS Environment for Urban Crisis Management, Case Study: District 8 of the Tabriz Municipality", pointing to the proximity of the Tabriz Metropolis to the Tabriz Fault Is one of the most dangerous faults in Iran, using 11 indicators to analyze the areas of risk (Pishgahi et al., 2011) In another research, Mohammadipour et al. (2015), "Analysis of vulnerability indices in urban worn out urban areas with the approach of earthquake crisis management: Case Study: Tehran's Cirrus neighborhood", using the AHP-FUZZY method for vulnerability analysis Seismicity of worn out tissues. The results show that the extent and coverage of the population of points with high and high vulnerability is higher and, in general, the range is highly vulnerable to all the physical factors analyzed against earthquakes.

In a paper titled "Earthquake hazard zonation in Turkey", Todd (2010) developed a map of the relative threat of earthquake hazard in Turkey and then used it to locate some urban uses.

Westen and Hofstee (2011) in a study by the International Institute of Aerospace and Earth Sciences entitled "The Role of GIS in Crisis Management and Disaster Rate in Urban Areas" identified crisis management in three areas: pre-crisis preparedness, crisis relief and The post-crisis reconstruction is being explored. This paper examines Colombia earthquake damage and relief in Colombia on January 25, 1999 using aerial photos and GIS maps using a digital elevation model.

In another study by Gokon and Koshimura (2012) at the Center for Sustainable Energy and Sustainable Economic Research, in a study entitled " Mapping of building damage of the 2011 Tohoku earthquake tsunami in Miyagi Prefecture," the study of earthquake warning systems and related GIS maps was carried out. Mapping, Seismic Modeling, and Crisis Management within the scope of the study, has been developing a map for the use of public and private bodies during the crisis.

Also, Sadeghi Far and Ebredari (2006) in a study entitled "Investigating the Role of GIS in the Management of Intelligent Accident Management", examined the need for a comprehensive crisis management plan to reduce the risks and losses caused by these incidents.

Dabbagh et al. (2020), in a study titled Optimal Location of Rescue Centers Using GIS and Multi-criteria Decision Making Methods (Case Study: Urmia City), with the aim of optimal location of earthquake temporary settlements according to various natural and human criteria. Bijnord city has been provided (slope, fault tolerance, proper access to military centers, medical treatment, training, etc.), each of which could provide a safe, safe environment away from high-risk environments.

\section{DATA AND METHOD OF WORK}

The city of Tehran, as the focus of the administrative, political, and economic concentration of the country's capital and as one of the most vulnerable areas of the earthquake, requires careful study and serious action. The faults in the Tehran area pass through or near the densely populated areas, and the possibility of occurrence of high damages in the event of activation of these faults is very high if these faults are activated, which requires priority areas to be checked. The location of a Tehran city in the southern slopes of Alborz and North Tehran fault, construction at altitudes, population, activity, 
concentration of capital ... Population and building of high towers in high altitudes, low passageways, heavy traffic roads, observance Failure to enforce construction laws all multiplies the magnitude of the earthquake mitigating impacts and causes the occurrence of other hazards and crises, and has created sensitive conditions for the region that, in the event of an earthquake, irreparable damage to the body Socio-economic city will leave (Berberian, and Yeats, 2017).

Existing evidence suggests insufficient attention to the prevention of natural disasters. Planning a disaster by reducing its adverse effects is considered as a positive step towards crisis management. The essential prerequisite for this is the acquisition of information that can be used in the decision-making field. In this context, the analysis of urban texture and the identification of vulnerable areas will be very beneficial and the capabilities of the GIS will be effective in collecting, categorizing and analyzing information mechanically. According to a joint study by the Japan International Cooperation Agency (JICA) and the Tehran Center for Earthquake and Environmental Studies, in the event of an earthquake in the capital, approximately 590,000 buildings will be severely damaged and some $\$ 220$ billion will be directly damaged to the city.

In the conditions of the region of Tehran, due to the geographical location of the bridge and the presence of many faults, the probability of a major earthquake is not far from the mind, and in the event of such an event, its financial, psychological and economic losses will be so much that its consequences will be nationalized also. will be. Identification of vulnerable zones and planning to retrofit and equip these locations, since disaster recovery is impossible, but it is possible to mitigate the damage that may result from it.

The existence of urban dense texture, historic texture, informal settlement and overcrowding, and its inappropriate spatial distribution, along with high construction density, have made this city vulnerable to an earthquake disaster. Investigating the content of the seismic map of Tehran's 354 neighborhoods in a region of Tehran: From 22 districts of Tehran, 9 regions are located within the main faults range. One of these areas located on the main fault zone is Area1.

The study area is located in the district of a municipality of Tehran. The geographical coordinates of this area on the north are limited to $1800 \mathrm{~m}$ high altitudes of the southern slopes of the Alborz mountains, south to Shahid Chamran highway, Azadi and Madras highway and Paul Ayatollah Sadr and from the west it is limited to the rivers of Derek and from the east to the end of the army highway - the cement plant and the source of oil in the north east of Tehran.

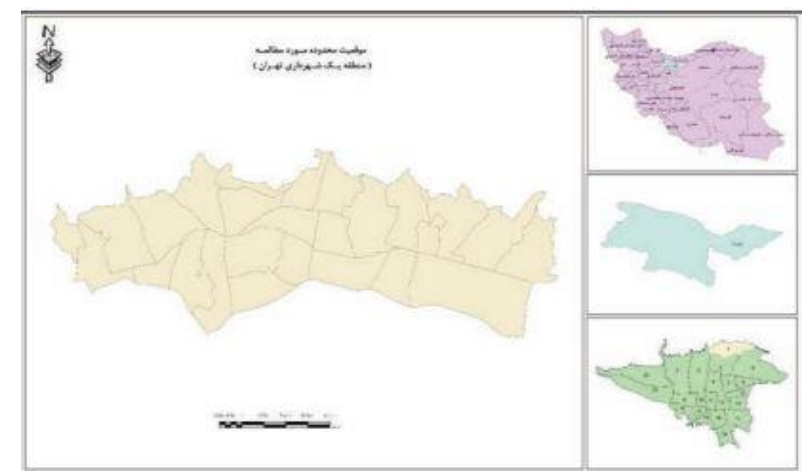

Figure 1. Geographic location of the study area

The present research is a research-laboratory type. Due to the goals of this research and the expected results, it is essential to carry out precise studies and achieve optimal results. Therefore, having accurate, reliable and reliable data is the first condition for achieving practical and appropriate results. The method used consists of three main steps: 1- Collecting data and information. 2 - Creating databases

Data collection: The data collected for the present study are the base map of the study area (District 1 of Tehran Municipality), the quality of the building, the number of floors, the facade (field survey), the life of the building, the area Plaques, road network and population of each parcel. 
Creating a Locally-Database: In this model, a spatial database of GIS is created that will create a real world in cyberspace. Geometric, descriptive, and physical characteristics of the objects in the virtual world are most closely resembles the fact that accurate conclusions can be drawn from the real world.

The basis of this database consists of a vector layer, which contains all the parcels within the scope of the study. The database consists of six layers that include: 1- Parcel area available to examine the effect of volume of each plaque on the rate of destruction. 2. The quality of the building of each parcel, which includes newly developed plates, can be maintained and worn and evaluates the strength of the structure against degradation, 3 . The number of floors in each parcel that assesses the impact of the weight of each plaque. 4. Materials to assess the resistance of the building. 5. Lifetime to estimate the resistance level. 6. The number of populations per parcel.

In order to connect these criteria together to estimate the damage to each parcel, Equation 1 was obtained Equation (1):

$\mathrm{V}=[(\mathrm{Q} \times \mathrm{q})+(\mathrm{O} \times \mathbf{0})+(\mathrm{M} \times \mathrm{m})+(\mathrm{F} \times \mathrm{f})] \times \mathrm{N} \times \mathrm{P}\left[5 \times 10^{\mathrm{n}-5}\right] \times \mathrm{S}$

In the above equation, $\mathrm{V}$ is the final vulnerability level of each building. $\mathrm{Q}$ is the weight related to the quality of the building and q to the weight of the newly built, canned and worn-out buildings. O Weight related to the life of the building and o Weight related to the buildings under the age of 15, 15-30 years and over 30 years. $M$ is the weight of the building materials and $m$ of the weight of the buildings with concrete structures, metal structure, brick and iron, brick, wood, and brick and wood. F Weight refers to the number of floors and f weight for buildings of 1 and 2 floors, 3 and 4 floors, 5 and 6 floors, 7 and 8 floors. The weight of each of the indicators and sub-indicators in the data processing section is explained. $\mathrm{N}$ is the normalized number corresponding to the area of each parcel, which is obtained by dividing the area of each property by the largest available area. $\mathrm{P}$ is the number of people in each building. The final part of the formula also relates to adding the effect of increasing the magnitude of the earthquake, so that in the equation $\mathrm{n}$, the variable is related to the magnitude of the earthquake. Finally, the $\mathrm{S}$ index relates to the impact of earthquake time on the extent of potential vulnerability and death. If the earthquake occurred in the morning, damage to buildings and casualties would be less, and if it happened at night, the opposite is true. By specifying the characteristics of each parcel and magnitude of the earthquake in the above formula, the probability of its vulnerability and its mortality is estimated.

\section{EXPLAINING THE RESULTS}

In this research, by using the GIS location system, we first determine the indices that affect the seismic vulnerability. Then, with the evaluation of each of these indicators, a matrix related to each one is presented, indicating the value and significance of each of these Indicators are in the building. After determining the indicators and sub-indicators effective, in the next step using the binary matrix, the value and importance of each of them is estimated in relation to the degree of impact on the vulnerability of the buildings. For this purpose, the matrix for this index was prepared to estimate the value of each sub-index. Therefore, 4 sub-life matrix matrices, building sub-indices, sub-classes of floors and building material indicators, and a matrix for estimating the value of each indicator were prepared. These matrices were filled by 21 experts. The arithmetic mean of each cell of the matrix was also calculated. Finally, using the Expert Choice software, the weight and value of each of the indicators and sub-indicators was estimated.

These indicators include: building life, building quality, number of floors, building materials. The subindices of each are as follows:

Omar Bana: under 15, 15 to 30 years old and over 30 years old.

Quality of the building: new, well maintained and worn out.

Number of floors: 1 and 2 floors, 3 and 4 floors, 5 and 6 floors, 7 and 8 floors.

Building materials: concrete skeleton, metal structure, brick and iron, brick and wood, brick and wood Mahootchi and Golmohammadi, 2018). 
Then, according to Table 1, the indices and sub-indices with the weight of each have been shown, which shows that the indicators of the quality of the building, the life of the building, the building materials and the number of floors, with a weight of 542/0, 306/0, 113 / 0 and 0.04 have the greatest impact on increasing the vulnerability of the building to the earthquake.

Tabla 1. Indicators and sub-indicators affecting the vulnerability of residential buildings along with the weight of each of them.

\begin{tabular}{|c|c|c|c|c|c|c|c|c|c|c|c|c|c|c|c|}
\hline \multicolumn{5}{|c|}{ Building materials $(113 / 0)$} & \multicolumn{4}{|c|}{ Number of floors $(0.04)$} & \multicolumn{3}{|c|}{$\begin{array}{c}\text { Quality of the } \\
\text { building }(542 / 0)\end{array}$} & \multicolumn{3}{|c|}{$\begin{array}{c}\text { Omar Bana } \\
(306 / 0)\end{array}$} & $\begin{array}{l}\text { Indicato } \\
r\end{array}$ \\
\hline 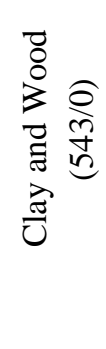 & 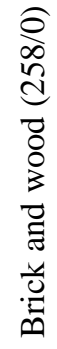 & 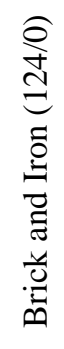 & 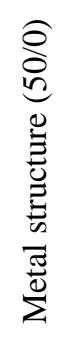 & 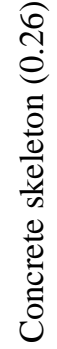 & 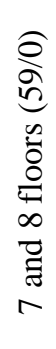 & 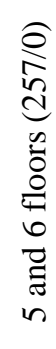 & 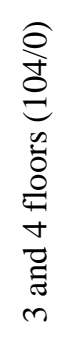 & 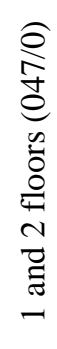 & 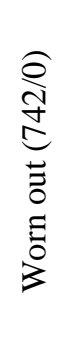 & 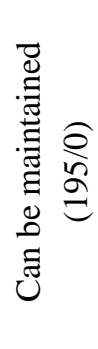 & 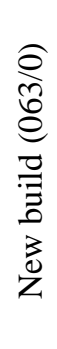 & 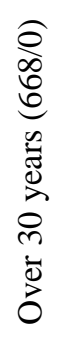 & 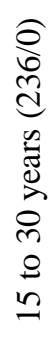 & 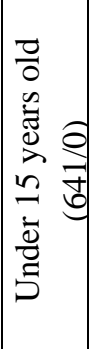 & $\begin{array}{l}x \\
\stackrel{x}{0} \\
. \Xi \\
z \\
\frac{0}{0} \\
\infty\end{array}$ \\
\hline
\end{tabular}

In order to determine the weight and ultimate vulnerability of each dimension against earthquake, the weight of the sub-index should be multiplied by the relevant index weight and summed up with the rest. As an example, in the calculation of a worn-quality parcel, aged 15 to 30 years, brick and iron and fivestory materials, ultimately weighs it in this way:

$((0 / 542 \times 0 / 742)+(0 / 306 \times 0 / 236)+(0 / 113 \times 0 / 124)+(0 / 40 \times 0 / 257))=0 / 498$

So, if we want to say a little about the vulnerability of the above-mentioned building, we say its vulnerability is $498 / 0$, and the higher the number, the greater the vulnerability.

Also adding two other indicators, which are the area of the property and the number of people in each building. Thus, by increasing the area of each section, the amount of casualties is also increased. Therefore, in order to calculate this index, the area of all parcels in the range is divided into the largest available area to reach the normal surface area numbers, which corresponds to each area index in each parcel, between 0 and 1 , in this case, whatever This number is closer to 1 , the probability of increasing casualties and closer to 0 is the probability of reducing casualties. Also, in order to influence the area index in the above formula, the resulting number is multiplied by the number of normalized area. To normalize the number, the area of each parcel is divided into the area of the largest available parcel.

$0 / 498 \times 0 / 68=0 / 33864$

Also, in the number of available individuals, according to the statistics obtained from the statistical blocks, the number of inhabitants in each building was estimated and multiplied by the final number obtained from the effect of the area of final weight on the casualties.

$0 / 33864 \times 5=1 / 6932$

The most important indicator of the magnitude of earthquake earthquake losses and losses. Earthquake magnitudes are directly related to the amount of energy released. The magnitude of an earthquake can be calculated by considering the range of oscillations on the map. Each earthquake has a large size that does 
not vary from the focal point of the earthquake, there are different scales for earthquake measurement. In 1395, Charles Richter defined the first large scale for earthquakes in Southern California.

With increasing earthquake magnitude, its power increases logarithmically. Accordingly, in order to influence the magnitude of the earthquake in the amount of possible damages and casualties, the final number obtained in the above sections is multiplied in the following formula (2):

$(5 \times \llbracket 10 \rrbracket \wedge n 5)$

$=66 / 84\left(5 \times 10^{6-5}\right) 1 / 6932 \times$

$=846 / 6\left(5 \times 10^{7-5}\right) 1 / 6932 \times$

In this formula, 5 magnitudes are placed for the magnitude of the earthquake, and $n$ is the magnitude of the earthquake. In this case, by increasing the magnitude of the earthquake from 5 to 6 magnitudes, the number 6 is replaced by the $\mathrm{n}$ variable. Thus, the earthquake magnitude 6 magnitudes increased 50 times the earthquake magnitude 5 magnitudes, and the earthquake magnitude increased to magnitude 7 in magnitude compared with the earthquake with a magnitude of 5 Richter 500 times.

Estimate the vulnerability of each building, taking into account all the effective indicators:

Based on the above, in order to influence all the effective indicators on the level of vulnerability of buildings (the quality of the building, the life of the building, the building materials, the number of floors, the area of the building, the number of people in each building and, ultimately, the magnitude of the earthquake) Equations 4 and 5 and the magnitude of the magnitude of the earthquake in these equations are estimated to be vulnerable and likely to be estimated.

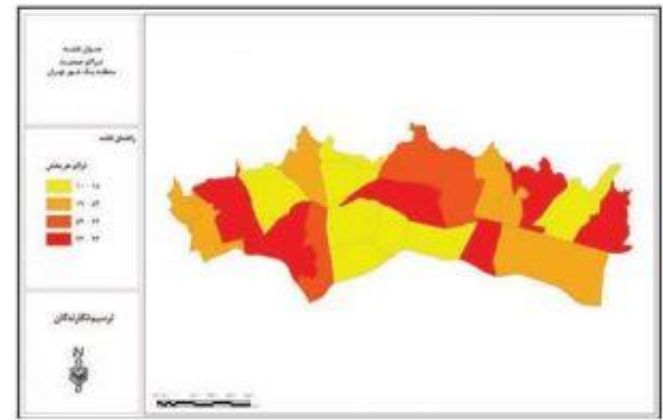

(a)

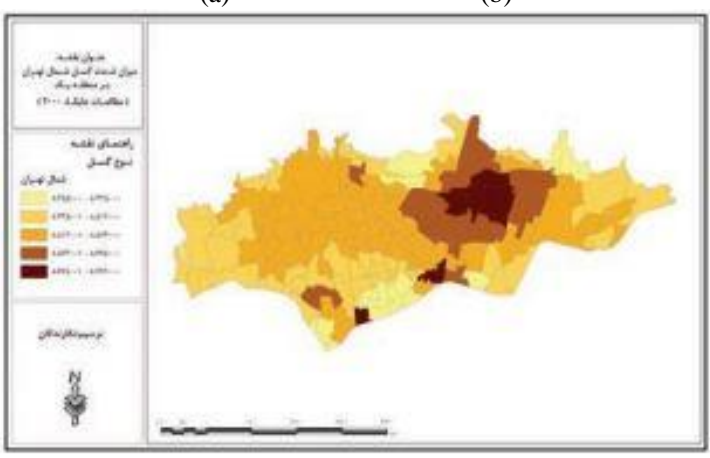

(c)

(b)

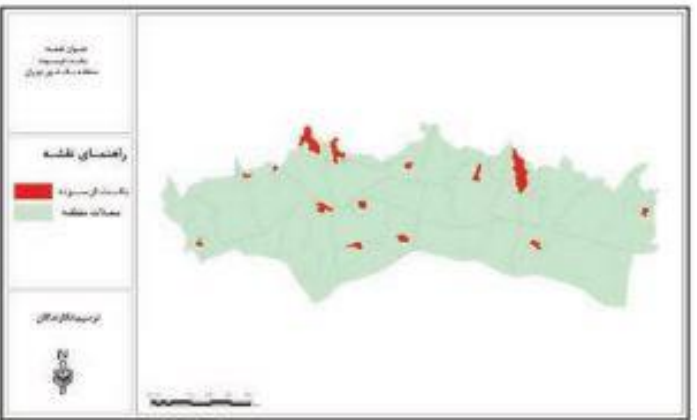

Figure 2. (a) Population density area. (b) Worn zone texture. (c) Severity of effect of Tehran fault on the area

The evaluated indexes in this area include construction factors and features of conscience. Factors such as the quality of the building (proper, repair, destructive), the age (ambient), the materials used (clay and mud, brick, stone, metal, concrete and wooden, etc.), the number of floors, has been evaluated. 
The probability of resistance of high-quality buildings (newly built) to earthquakes is higher than that of ruined buildings. One of the main factors in the amount of casualties and damage caused is the type of structure of the buildings. Buildings with metal skeleton, concrete, brick and mud and mud, against the earthquake and the resulting waves show a different resistance, and also the extent and the manner of damage are different in each and every one. Buildings with all wood materials, buildings in which wood is used as the main building material (ferry), have a relatively good (good) resistance to earthquakes. In buildings with wooden materials and saddle and ceiling roofs, there are many casualties. The collapse of the large amount of soil causes the respiratory tract to be lost to the injured people in the submarine, so the number of deaths in these areas will increase.

\section{CONCLUSION}

In this research, according to the specific conditions of the city of Tehran and the use of six main indicators: building life, building quality, number of floors, building materials, property area and number of people, characteristics of the study area to express the vulnerability of the area to earthquake cases Attention has been paid. Finally, using Expert Choice software, the weight and value of each of the indices and sub-indicators were estimated based on each of the information indicators in the spatial information system environment. The results show that the north of the region, streets and streets with low width and high buildings, worn out texture and ruined sites, and ... are insecure and vulnerable areas of the earthquake against earthquakes. Also based on the results of the research, the GIS spatial information system was able to provide significant information during the earthquake on the magnitude of the damage and casualties. Of course, this largely depends on the information and indicators that come from the area. The results indicate that the extent of destruction and consequences of the earthquake depends on the determined indicators, including the quality and the area of the building.

\section{REFERENCES}

Gokon, H., \& Koshimura, S. (2012). Mapping of building damage of the 2011 Tohoku earthquake tsunami in Miyagi Prefecture. Coastal Engineering Journal, 54(01), 1250006.

Dabbagh, R., \& Ahmadi Chokalaei, H. A. C. (2020). Optimal Location of Rescue Centers Using GIS and Multicriteria Decision Making Methods (Case Study: Urmia City). Quarterly Scientific Journal of Rescue and Relief, 12(1), 0-0.

Berberian, M., \& Yeats, R. S. (2017). Tehran: An earthquake time bomb. Tectonic Evolution, Collision, and Seismicity of Southwest Asia: In Honor of Manuel Berberian's Forty-Five Years of Research Contributions, 525, 87.

Mahootchi, M., \& Golmohammadi, S. (2018). Developing a new stochastic model considering bi-directional relations in a natural disaster: a possible earthquake in Tehran (the Capital of Islamic Republic of Iran). Annals of Operations Research, 269(1-2), 439-473.

Entezari, Vahid. (2002). Hospital disaster plan protocol according to Hospital Emergency Incident Command System (HEICS) In Iran Ministry of Health and Medical Education.The collection of disaster health care and management bylaws, (Volume 1). Tehran: Iran Ministry of Health and Medical Education.

Amini Hosseini, Kambod; Pishnamazi, Parvaneh. (2011). Investigating how to report on Roodbar and Manjil and Bam earthquakes. Scientific Journal of Extension of Seismology and Earthquake Engineering Researches, thirteenth year, Issues 47 and 48, pp. 65-57.

Pishnamazi, Parvaneh, (2015). Essentials of media efficiency in earthquake coverage; The role of news managers in crisis management .shargh newspaper, Thursday 3 at 2015: 11. 
Hosseini, Maziar, (2008). Crisis Management. First Printing, Tehran City Crisis Management and Prevention Organization.

Longley, P. A., Goodchild, M. F., Maguire, D. J., \& Rhind, D. W. (2015). Geographic information science and systems. John Wiley \& Sons.

Torabi, shie; Habibi, Kamal. (2010) .Investigating the vulnerability of cities to earthquakes using the method of inverse hierarchical analysis of IHWP and GIS,Case study: District 6 of Tehran Municipality. Proceedings of the Fourth International Congress of Geographers of the Islamic World.

van Westen, C. J., \& Hofstee, P. (2000). The role of remote sensing and GIS in risk mapping and damage assessment for disasters in urban areas. Fernerkundung und Naturkatastrophen, 7, 442-450.

Sadeghi far, Jamil; Abredari, Hasan. (2006) .Investigating the Role of GIS Geospatial Information Systems in Accident Management. Third International Congress on HealthTreatment and Crisis Management in Incidental Disasters, Tehran.

MohammadiPour, Saber. (2014). Analysis of vulnerability indices in urban worn out urban areas with the approach of earthquake crisis management: Case Study: Tehran's Cirrus neighborhood. $\mathrm{PhD}$ thesis of geography and urban planning, Assistant Professor Dr. Pourahmad, Ph.D. Ph.D. Farhoodi, University of Tehran, Faculty of Geography, Tehran. 